Realising the rhetoric: Refreshing public health providers' efforts to honour Te Tiriti o Waitangi in New Zealand

Came, $\mathrm{HA}^{1}$, McCreanor, $\mathrm{T}^{2}$, Doole, $\mathrm{C}^{1}$, and Simpson, $\mathrm{T}^{3}$

${ }^{1}$ Faculty of Health and Environmental Sciences

Auckland University of Technology

Private Bag 92006

Auckland 0627

New Zealand

6499219999

Heather.came@aut.ac.nz

Claire.doole@aut.ac.nz

${ }^{2}$ Te Rōpū Whāriki

Massey University

PO Box 6137

Wellesley Street

Auckland 1141

New Zealand

6493666136

T.N.McCreanor@massey.ac.nz

${ }^{3}$ Health Promotion Forum

PO Box 99064 Newmarket,

Auckland 1149

New Zealand

6493003736

trevor@hauora.co.nz

Corresponding author: heather.came@aut.ac.nz

This work was supported by the Faculty of Health and Environmental Sciences, Auckland University of Technology under Grant CGHS 06/14. 


\section{Ethnicity and Health}

\section{Realising the rhetoric: Refreshing public health providers' efforts to honour Te Tiriti o Waitangi in New Zealand}

\section{Abstract \\ Objectives}

This paper investigates the ways two groupings of public health providers, public health units and non-governmental organisations meet their Te Tiriti o Waitangi obligations in terms of service delivery to Māori.

\section{Design}

A nationwide survey of public health providers $(n=162)$ was conducted between November 2014 and May 2015. Semi-structured telephone interviews were conducted with public health managers. Qualitative and quantitative data was collected. Participants were asked about the effectiveness of service delivery to Māori and how this was monitored. This paper presents a qualitative analysis of the data.

\section{Results}

Some public health units (PHUs) reported actively working with Māori, Te Tiriti o Waitangi and reducing health disparities. Direct Māori engagement with development and delivery of programmes was viewed by many as essential. Strategies included designated PHU staff in positions of responsibility and formal partnerships with mana whenua (local Māori with territorial rights), providing operational and strategic guidance. Some PHUs implemented staff development in cultural competencies. On the other hand non-governmental organisations (NGOs) responsiveness to Māori was variable. Some NGOs described prioritising service delivery and programmes for Māori to reduce health disparities. Others reported that the focus of their service delivery was for European or other non-Māori ethnicities and that a lack of resources or past difficulties engaging with Māori were barriers.

\section{Conclusion}

Māori, in common with other indigenous groups, have compromised health status. Public health has an ethical commitment to reduce health disparities. New Zealand has a unique tool in Te Tiriti o Waitangi for engagement with Māori. Advancing Te Tiriti obligations and tino rangatiratanga (Māori control over things Māori) in everyday practice has the potential to address inequities.

Keywords: New Zealand, Te Tiriti o Waitangi, Treaty, public health providers, survey, indigenous 


\section{Introduction}

While publicly funded health services (hospitals, community clinics, nursing and health promotion) have long been part of the local health infrastructure, public health providers (PHPs) emerged in the New Zealand context during the neoliberal reforms of the early 1990s. These reforms established a competitive contracting environment within the health sector and beyond (Mills and Broomberg 1998, Upton 1991). These developments were part of a wider international trend of 'social and economic adjustment' pursued by neoliberal governments (Kelsey 1991). Reforms in the health sector resulted in the uncritical application of business models and practices to areas traditionally outside the reach of the market, (Easton 2002) in the name of economic efficiencies.

By the late 1990s, public health services including health promotion, health protection, immunisation education, smoke free environments, sexual health, well child campaigns and other initiatives were being delivered by public health units (PHUs), non-governmental organisations (NGOs), and Māori health providers. While some Primary Health Organisations (PHOs) also deliver selected health promotion and related public health services, this paper focuses on data about the experiences of PHUs and NGOs and their delivery of public health services to indigenous Maori communities, gathered in a national telephone survey in 2015.

Historically PHUs emerged out of the regional offices of the Department of Health (now the Ministry of Health) in the early 1990s, following the separation of health services into personal and public health around the time of the development of the Ottawa Charter for Health Promotion (WHO 1986). PHUs employ statutory officers, designated by the DirectorGeneral of Health under the Health Act 1956, and deliver both health promotion and health protection services. PHU contracts require delivery of services to the entire population within their geographic region inclusive of Māori. NGOs are diverse independent organisations that provide national, regional and local services. NGOs have individual constitutions, governance arrangements, and often receive funding from community grants, or private industry in addition to governmental funding. They are frequently registered charities and may have a clear social mission. NGOs may be geographically orientated or focus on a particular speciality within public health practice.

Through these ideologically driven changes the public health sector has experienced significant restructuring to form market models, and 'user-pays' practices that reflect the political orientation of the respective governing coalitions (Quinn, 2009). Unsurprisingly these changes have affected most heavily those least able to afford to pay for healthcare. The consistent production of inequitable health outcomes between Māori and other New Zealanders now seems an enduring feature of the health sector (Ajwani et al. 2003, Penno, Gauld, and Audas 2013, Pōmare 1980, Pōmare and De Boer 1988, Pōmare et al. 1995, Reid and Robson 2007).

The persistence of these inequities provides significant scope to strengthen practice (Signal et al. 2007). Given the deeply entrenched nature (Signal et al. 2013) of the problem it seems a planned systems change approach (Griffith, Mason, et al. 2007) aligned to existing quality assurance systems holds much promise (Ministry of Health 2003). According to Jansen et al, (2008) research on the key barriers and enablers of access to care shows that: 
The capacity of the health sector to meet the needs of these groups is questionable at every level - from the individual patient to the interactions between patients and health professionals to the health system of a country ( $\mathrm{p} 14)$.

They have used a form of structural analysis developed from Lafond, Brown, and Macintyre (2002) that encourages a focus on the capacity of healthcare systems, organisations and personnel to understand the development and potential improvement of service providers to meet Māori healthcare needs. Sheridan et al (2011) in a nationwide study of DHBs identified the need for a systematic approach to achieve health equity, building on pockets of exceptional practice. Came's (2014) work recommended strengthening decision-making, developing cultural and political competencies, strengthening consultation practices and reviewing evidence to address inequities and racism within public health. Cram's (2014b, a) studies of Māori access to healthcare suggests focussing on the domains of leadership, knowledge and commitment.

\subsection{Te Tiritio Waitangi and public health}

Te Tiriti o Waitangi has a multiplicity of meanings within New Zealand political and sociocultural contexts. It is, however, widely recognised as the founding document of the colonial state of New Zealand (Orange 2011). There are important technical distinctions within treaty discourses between i) Te Tiriti o Waitangi, the Māori language text, ii) the Treaty of Waitangi, the English language version, and iii) the Crown-defined treaty principles.

The Māori text - Te Tiriti o Waitangi - established the terms and conditions of British settlement and reaffirmed Māori sovereignty (Healy, Huygens, and Murphy 2012). Article 1 of Te Tiriti requires the (settler) government to engage in honourable kāwanatanga or governance to address the particular interests of Māori alongside those of other New Zealanders. Article 2 affirmed Māori tino rangatiratanga or sovereignty, guaranteed to Māori the protection of taonga (treasures) such as health, land and Te Reo Māori (Māori language) and made provisions to safeguard Māori interests in the sale of any land (Healy, Huygens, and Murphy 2012). Article 3 granted Māori ōritetanga the same rights and privileges as British subjects.

According to Fletcher's (2014) recent re-examination of the English version, the Treaty enabled government over British settlers and maintained Māori tribal custom for the protection of Māori-consistent with colonial policy at the time. Both the Māori text and the English version are recognised by the New Zealand Government through the Treaty of Waitangi Act 1975, which established the Waitangi Tribunal. ${ }^{1}$ Under international law however, the legal doctrine of contra proferentem applies and the Māori text is the authoritative text. To add to this complexity, Hayward (1997) has identified over thirty-four different treaty principles developed by Crown agencies in relation to the Treaty of Waitangi.

Durie (1998) argues Māori put limited credence on these sets of treaty principles and instead focus on the actual articles of Te Tiriti. More recently the Waitangi Tribunal (2014) has ruled that signing Te Tiriti by rangatira Māori in 1840 and thereabouts in no way constitutes a cession of sovereignty. While the meaning of this finding is still being digested and worked through, it now provides an additional impetus to work for constitutional transformation

\footnotetext{
${ }^{1}$ The Waitangi Tribunal is a permanent Commission of Inquiry to investigate breaches of Te Tiriti o Waitangi and/or the Treaty of Waitangi by Crown Ministers and officials.
} 
(Matike Mai Aotearoa 2016) toward structures in which equity in all areas, including health, is central to new constitutional arrangements.

The complexities of this contested ground aside, Te Tiriti established the foundation upon which settler peoples can justly immigrate and reside in New Zealand, and is widely held to constitute a partnership between indigenous and settler peoples with mutual roles and responsibilities. Over 170 years the colonial process has seen significant erosion of Māori power and self-determination and the steady rise of power in the settler dominated state, despite Māori resistance. Arguably, Treaty-based aspirations and pursuit of social equity fall on both treaty parties so that the domain of health equity between Māori and non-Māori as a requirement for social justice and honouring Te Tiriti (Reid and Robson 2007, Sheridan et al. 2011, Came and McCreanor 2015), is a key responsibility of the state. Beyond an equity imperative, Treaty obligations extend to ensuring Māori input into decision-making.

The Treaty of Waitangi formally entered into 'mainstream' public health policy discourse in 1988 when the Director-General of Health, Dr George Salmond (9 May 1988) penned a memo to the health sector, requiring engagement with the Treaty (Durie 1998). Prior to this Māori had a long tradition of articulating the importance of Te Tiriti in relation to hauora (health) (Lange 1999, Dow 1999). Through the 1990s and 2000s various health policies made reference to the Treaty, including Whaia te Whanaungatanga (Ministry of Health 1998), New Zealand Health Strategy (King 2000), and He Korowai Oranga (Ministry of Health, 2014). The New Zealand Public Health and Disability Amendment Act 2010, the legislation that underpins the current health system, requires all health providers to address health inequities and engage with the Treaty of Waitangi.

Since 1840 there have been 89 health-related deeds of claims logged with the Waitangi Tribunal citing breaches of Te Tiriti o Waitangi by Ministers of the Crown and Crown officials (Came 2012). Many of these breaches are comprehensive in nature and are related to the historical alienation of whenua (land) from whānau (families) and the disruptions of customary practices of land tenure. Several claimants explicitly noted the acts of war initiated by the Crown in pursuit of land and the resulting loss of life. The decimation of the Māori population through the introduction of alcohol, tobacco and new diseases were also identified as a direct negative health impact of Crown practices. Others noted the institutional racism embedded within the administration of the health sector.

Treaty Understanding of Hauora in Aotearoa-New Zealand (TUHA-NZ) remains a landmark document in relation to Te Tiriti and public health (Health Promotion Forum, 2000). These practice guidelines were in part developed to resolve the active debate about the place of the Ottawa Charter (WHO, 1986) versus the place of Te Tiriti in New Zealand based health promotion. TUHA-NZ established health promotion goals for each article of Te Tiriti. Together these goals and their related strategies formed an action plan of how to operationalise Te Tiriti. Influenced by the contributions of Ramsden (2002) and Durie (1998), a variety of other cultural and treaty audit tools have been developed to assess and maximise responsiveness to Māori. These include, amongst others, The CHI Model: Culturally Appropriate Auditing Model (Durie 1993); a tool to enable service delivery to be audited against Māori development, health gain, cultural beliefs and values. He Taura Tieke (Cunningham 1995) is a comprehensive checklist to access effectiveness of service delivery to Māori. The Whānau Ora Health Impact Assessment (Ministry of Health 2007) establishes a process to assess the impact of policy and/or initiatives on whānau health and wellbeing. 
The Health Equity Assessment Tool (Ministry of Health 2004) focuses on health equity tools but also addresses how agencies address the Treaty of Waitangi.

Therefore, in the context of New Zealand, all PHPs and practitioners are required to consider the interests of Māori in all that they do, whether it be developing, delivering or evaluating health services. For practitioners, these requirements are embedded in public health ethical guidelines (Public Health Association 2012) and competency documents (Health Promotion Forum 2011, Public Health Association 2007).

This paper investigates how two groupings of public health providers, PHUs and NGOs are engaging with their Te Tiriti obligations and service delivery to Māori. Findings were derived from thematic analyses of the qualitative sections of a nationwide survey of public health providers. The authors offer strategies to strengthen existing service delivery, drawing on their long-time engagement with the anti-racism and tino rangatiratanga movements.

\section{Methods}

In December 2010 Came (2013) conducted a nationwide telephone survey of PHPs as part of a study into institutional racism within the public health sector. This 2014/15 study utilised a list of contracted public health providers furnished by the New Zealand Ministry of Health, applying the same survey tool as Came's earlier study to track health providers' experiences of their funders. Over the recruitment period (Nov 2014-May 2015), 162 providers were enrolled to this telephone survey; a response rate of $75 \%$. Semi-structured interviews of about 15 minutes were conducted with the managers responsible for the providers' public health contract(s). Informed consent was negotiated with participants and interviews were transcribed by the research team. Participants had the opportunity to make alterations to their transcripts within an agreed timeframe before finalisation. Ethics approval was secured through the Auckland University of Technology Ethics Committee (No. 14/229).

All twelve PHUs (12/12) participated in the study. Some fifty-five NGOs (55/70) participated in the study, making an overall response rate of $82 \%$ from this cohort of providers. We were unable to get hold of the relevant managers at six NGOs during the recruitment period and seventeen declined to participate. The participating NGO sample was a cross section of local and national providers and covered a good geographic spread of Aotearoa. All participant organisations held a public health contract with either the Ministry of Health or a district health board. Other types of PHPs, surveyed but not included in this paper, were PHOs, Pacific and Māori PHPs. PHOs have a proportionately lesser focus on public health delivery; their engagement with Māori would be more usefully discussed in the context of primary health care, hence their exclusion from this paper. Likewise, Pacific and Māori run and governed health providers have been excluded in order to highlight non-Polynesian perspectives.

Within the survey, providers were asked to self-assess the effectiveness of their service delivery to Māori and then invited to comment on their rating. Following this providers were asked how they monitored the effectiveness of their delivery to Māori and this paper focuses on analysing the qualitative data from these responses.

Data were examined using Braun and Clarke's (2006) steps of thematic analysis as a way of categorising participants perspectives into meaningful themes. Firstly two authors independently used close reading processes to familiarise themselves with the data and generate and populate codes using Nvivo software (Bazeley and Jackson 2013), which was 
then used to search for data excerpts common to themes and check for connections among themes. Discursive analysis of pattern and variation in the thematic data were used to define and name themes and to guide the description and write-up of the analysis. This interpretative work was informed by the authors' critical understanding of anti-racism praxis.

\section{Results}

Themes highlighted from PHUs in the current analyses include the importance of this work, that it is developmental and relational in nature. Many PHUs had Māori roles and dedicated projects they were pursuing. The effectiveness of the work was measured through using existing evaluative frameworks and feedback from Māori. Themes from NGOs revealed two cohorts: one with a strong commitment to Te Tiriti and Māori health, the other rich in justifications for why they provided limited or no service delivery to Māori. The former cohort often had structural responses to Te Tiriti, relationships with Māori, were building capacity and have pilot projects they were advancing. The effectiveness of their delivery was measured against plans and feedback from Māori.

These themes are presented separately and then discussed before the authors recommend pathways toward realising the policy aspirations of honouring Te Tiriti.

\subsection{Public health units}

All the PHUs were clear that Māori health was important and many stated their substantial and ongoing commitment to addressing health inequities. Several providers reported it was a "constant focus", a "priority", or something that is taken "seriously". Perhaps reflecting the Treaty obligation of district health boards to be responsive to Māori, all the PHUs ranked themselves either strong or developing in their service delivery to Māori.

Providers were careful in how they described their service delivery, emphasising the developmental nature of the work. One noted: "developing is the 'politically correct' way of putting it. Another said "you'd be arrogant to say it's [service delivery] strong". This developmental state is evidenced in PHUs commitment to ongoing professional development programmes to build and extend the cultural competencies of staff. They recognise that the work of inequalities is not simply the task of Māori, and move to upskill all staff spreading the load in a manner consistent with the aspirations of Te Tiriti.

A number of PHUs emphasised their work was relational, and they worked in partnership with mana whenua. They noted these collaborations tended to be operational, around specific projects, rather than at a governance or strategic level. An example of these connections was a PHU, whose team had been formally welcomed onto all the marae ${ }^{2}$ in the district, clearing the way for informal access into the future. This acknowledgement and adoption of Māori protocol may sound insignificant but represents a genuine and future-oriented effort to engage with the worldviews, beliefs and practices of PHU's treaty partners in ways that represent a partial fulfilment of their Treaty obligations.

Many PHUs reported specific Māori staff within their team and other individuals that championed Māori health. Other PHUs emphasised that within the wider DHB that housed them, there were designated Māori staff such as Managers, Advisors, Directors, with whom they worked closely and provided operational and strategic guidance. The achievement of

\footnotetext{
${ }^{2}$ Marae is the open area in front of a whare nui (meeting house) where formal greetings and discussion occur.
} 
levels of Māori staffing and involvement represents progress in the direction of treaty obligations.

PHU commitment to Māori health was also evidenced in work plans and focus on areas relevant to disparities such as tobacco control, obesity and rheumatic fever (Marriott and Sim 2014). One PHU demonstrated their commitment to Māori health through devoting one morning a month specifically to focus on Māori health, while another chose to work with Māori as well as western health models. These incremental steps can both build Te Tiritibased futures while also providing immediate relevance to more equitable practice.

So how did PHUs assess their service delivery to Māori? Evaluation approaches were variable. Several reported monitoring prioritised service delivery, aligned with DHB wide ethnic specific indicators. Some reported working with evaluation frameworks such as $\mathrm{He}$ Taura Tieke (Cunningham 1995) and results based accountability (Friedman 2005) to monitor effectiveness. One PHU had an in-house evaluator to track effectiveness, while another reported deliberately prioritising service delivery to Māori, Pacific and high deprivation communities, based on analysis of data broken down to census area units.

A relational approach was described by several other PHUs, whereby external and internal relationships with Māori provided advice on progress. Māori involvement with the development and delivery of programmes was seen as critical to assessing and achieving effectiveness. A striking example of the success of involving Māori are the innovations in the field of sudden unexplained death in infancy (Abel and Tipene Leach 2013) and improved health outcomes around rheumatic fever (Coleman 27 August 2015). Meanwhile one outlier PHU confirmed that they did not specifically monitor their delivery to Māori as they felt it was the focus of their entire public health contract.

\subsection{Non-governmental organisations}

Within the NGOs respondents there was diverse engagement with Te Tiriti and service delivery to Māori. One proactive cohort of NGOs embraced their commitment to Māori health and indicated they worked "really hard" in this area. The other disengaged cohort conceded they paid limited attention to Māori health.

The first proactive cohort had frequently implemented structural responses to Te Tiriti. Several described themselves as treaty-based organisations, and these claims were solidified through governance structures, constitutions and charters. Many NGOs reported having 'living' Māori responsiveness plans in place. Others had negotiated formal bicultural relationships with Māori providers and/or iwi (tribes) to strengthen and align their work. These structural and strategic arrangements are evidence of an orientation to meet obligations under Te Tiriti.

As with PHUs, and in the absence of in-house Māori staff, some NGOs proactively invested in developing their internal cultural competence in order to deliver effectively to Māori. Access to kaumātua (Māori elders) and/ or cultural advisors via advisory groups and the like was enjoyed by several providers. One NGO had secured access to a taumata (panel of elders) to tautoko (support) their work. These initiatives improve the likelihood of effective engagement.

This cohort reported engaging in targeted delivery to Māori communities to achieve specific components to their contracts. While certain commentators may be critical of these kinds of 
arrangements, seeing them as special or privileging, in a Treaty framework these measures are justifiable on the grounds that equitable outcomes may require unequal input. Specific examples of action taken to engage with and support Māori were working with mana whenua in conference planning and advocating for the retention of a unique kaupapa (mission) Māori service. Others had engaged in pilot projects to strengthen their delivery to Māori.

The disengaged cohort disclosed an eclectic range of justifications for their weak or absent service delivery to Māori. Several clarified that they were a universal service or that they were an ethnic specific service (refugee, new migrant or Pasifika) suggesting they had no Te Tiriti obligations. One provider clarified: "they need to come to us, we don't go out, we are mainly European". Such rationale coheres with mono-cultural or 'multicultural' models where the default setting is that of the settler majority.

One provider indicated a belief that Māori were not interested in their field of public health, while another NGO cited the lack of qualified Māori health professionals in their area of interest as a cause of their current limited level of service delivery. Another NGO indicated they did not deliver services to Māori, as they believed other agencies did that work; a further provider asserted they had limited time, resources and money so did not have capacity to deliver. These explanations reflect the economic rationalism introduced and entrenched via neoliberalism and represent the degree to which this ideology has marginalised Te Tiriti obligation within the frame of public health provision.

The proactive cohort measured the effectiveness of service delivery to Māori in a variety of ways, usually through specific Māori health plans. Some utilised standard evaluation processes such as tracking epidemiological data, demand on services, stakeholder and participant feedback. Some had developed purpose built evaluation systems and databases, others used Friedman's (2005) results based accountability. One reported having an ethnicity project underway to strengthen evaluation processes. For some, tracking service delivery was central to their quality assurance systems and one provider indicated the use of Te Wana accreditation system. This programme (Buetow and Wellingham 2003) has particular indicators around working with Te Tiriti o Waitangi and exposing and addressing practices that enable health inequities and racism.

This cohort often also had a relational approach, and consulted and worked with Māori as they developed work plans and priorities and delivered services. This engagement with Māori was with in-house Māori staff and through formalised relationship through governance structure and partnership arrangements. These Treaty-oriented responses to the challenges of Māori service provision by NGOs indicate the willingness to pursue creative partnership type solutions where service needs cannot be met from within.

The disengaged cohort indicated they did not directly monitor service delivery to Māori, they frequently reported they did not 'have a formalised system'. One disclosed when they had attempted to work with Māori it has been a 'fail' so they had not tried again. An outlier participant indicated that they guessed the ethnicity of their clients monitoring purposes. Another shared that it was difficult for them to engage effectively as they were perceived as being a 'European' organisation.

\section{Discussion}




\subsection{Public Health Units}

If one accepts that PHUs are quasi Crown entities, situated as they are within DHBs, then there are particular obligations to engage with Māori. PHUs should therefore be forming relationships with i) local hapū (sub tribes) ii) Māori or iwi (tribal) health providers who often have particular responsibilities for health, and iii) other diverse Māori whānau (families) and communities. External engagement needs to be at both a strategic and operational level. Internal dialogue with Māori staff, however valuable, is different from external relationships.

Māori health plans need to reflect Māori aspirations. These aspirations are revealed through ongoing dialogue and are increasingly articulated in hapū and iwi led health plans. Corporate DHB developed Māori health plans may reflect other centrally driven priorities. A critical question for PHUs as they wrangle the competing demands on their time and resources is whose aspirations are being pursued? If we are having a treaty-based conversation why not flip the conversation: what can PHUs/ DHBs contribute to hapu and iwi plans?

It is pleasing to see the consistent commitment from PHUs to addressing health inequities. For Māori the need to address health disparities is more than a political or legislative imperative, it is a matter of life and death. The challenge is to deliver consistently well to Māori communities.

It is positive to see PHUs commitment to developing and strengthening cultural competencies within their respective teams. The authors offer the challenge to step beyond individual cultural competencies to collective cultural and political competencies (Came and da Silva 2011). Building sustainable systems is the core of public health. Roles and processes need to be embedded. Relying on pockets of individual excellence is unlikely to bring sustained change, rather systems change seems a more potent pathway (Came and McCreanor 2015). Correct pronunciation of Te Reo Māori and a working knowledge of tikanga is basic core competency of all public health practitioners (Public Health Association 2007). The next step is developing expertise in detecting and preventing institutional racism, and maintaining and advancing long-term relationships with Māori that can withstand changes in personnel.

The introduction of results based accountability within the health sector may be a positive development. A note of caution, given its obvious approval by governments of economic rationalism, is to question whether it is going to capture progress towards Māori aspirations: when and how were Māori asked if this framework could work for them? We know that $H e$ Taura Tieke (Cunningham 1995) for instance is effective in this context, alongside other kaupapa Māori frameworks already developed by Māori circulating within the health system. Those PHUs that do not monitor service delivery to Māori are potentially inadvertently enabling maintenance of health disparities.

\subsection{Non-Governmental Organisations}

The process for NGOs delivery to Māori differs from PHUs, as NGOs are not quasi Crown agencies. NGOs have greater scope for independent action tailored to the communities they serve. In accepting public health monies from the Ministry of Health and DHBs, NGOs do however acquire a clear contractual requirement to address health disparities and deliver effectively to Māori as part of the entire community.

NGOs, like PHUs, need to develop and maintain relationships with Māori at operational and strategic levels. Clearly a cohort of NGOs are doing well in this critical area, particularly 
those that have committed to the complex journey to become Treaty-based organisations. The creative and structural responses to the challenge of Te Tiriti o Waitangi in governance structures and constitutions alike bode well for health service delivery to Māori and reduced health inequities. Living Māori health plans, which at their best reflect Māori aspirations, are also a powerful step in this direction and are embraced by many NGOs.

In contrast, the range of excuses and apologies for lesser levels of service delivery to Māori by the disengaged cohort although undeniably creative, are disappointing. Mechanisms are available whereby practitioners, portfolio managers and senior managers alike can be accountable for their practice in relation to Māori health (Cunningham 1995, Durie 1993). The challenge in consolidating practice within some NGOs seems to be about moving from occasional projects with Māori to strengthening everyday engagement with Māori, in order for engagement to become ordinary and in the centre, rather than episodic and peripheral.

As with PHUs, collective cultural and political competencies which withstand key personnel changes need to be pursued (Came and da Silva 2011). As Signal (1998) argues, health promotion work by its nature is political as it seeks to mobilise social change. Normalising reflective practice (Fleming 2007) is useful to develop and maintain all sorts of competencies relevant to this area of work. Robust planning and evaluation are central to effective practice regardless of who is delivering to whom (ANZEA and SUPERU 2014, Public Health Association 2007). Ensuring Māori involvement in planning, implementation and evaluation maximises the possibilities of positive Māori health outcomes. Te Wana accreditation system (Healthcare Aotearoa 2007) has a proven track-record, putting Māori concerns in the centre and challenging racism. Independent monitoring systems combined with structural inclusion of Māori, and long-standing relationships with Māori seem to be critical ingredients to successful delivery to Māori.

\section{Conclusion/Recommendations}

Within the New Zealand context, Te Tiriti holds a unique place and is a legislative, policy and professional imperative for the public health community. Fifteen years has passed since the release of TUHA-NZ (Health Promotion Forum 2000). PHUs and NGOs are variously responding to the challenge of how to apply Te Tiriti. Entrenched health inequities between Māori and non-Māori (Marriott and Sim 2014) suggest there are still opportunities for improvements in practice.

Distilled from the data from this survey and the knowledge utilised in the authors' long-time engagement with anti-racism praxis in Aotearoa, we offer the following points as a challenge to refresh how PHU and NGOs might engage with Te Tiriti.

Those that are doing this mahi (work) well have invested time and energy in forming and maintaining relationships with a range of Māori stakeholders. Sometimes these relationships are formalised, sometimes more ad hoc. It is through these external relationships that providers are able to learn about the priorities of Māori partners and then, when possible, weave these into complimentary work plans. Generic health providers that position themselves to enable Māori aspirations around tino rangatiratanga were scarce within the survey. Such goals can only realistically be achieved through ongoing dialogue and attempts at partnership, power sharing (Huygens 2006) and systems change (Came and McCreanor, 2015), and indeed constitutional transformation (Matakite Mai, 2016). 
Those providers that seem to do this work best have made a political commitment to address health inequities, and to work with Te Tiriti o Waitangi. The challenge for generic providers seems to be about moving past policy and mission statement rhetoric into making working with Te Tiriti ordinary and everyday practice. To normalise working with Te Tiriti requires organisations to invest in developing collective political and cultural competencies (Came and da Silva 2011). This can involve deliberately recruiting staff with those skills and/or developing them within the existing team. For those organisations ready to go further, formal plans need to be written and regularly reviewed. A systems change approach to quality assurance around equity and challenging mono-cultural practice seems a promising pathway forward (Came and McCreanor 2015, Griffith, Childs, et al. 2007).

\section{Acknowledgement}

Our thanks to the participating public health providers for sharing your korero with us. We wish you well in your ongoing efforts to honour Te Tiriti o Waitangi. The journey of decolonisation is a challenging and potentially long but the costs of inaction remain unacceptably high. Thanks to the STIR: Stop Institutional Racism Now members and Shayal Mala for your contribution to this work. Thanks to Jonathan Fay for comments on the draft. 


\section{References}

Abel, Sally, and David Tipene Leach. 2013. "SUDI prevention: A review of Māori safe sleep innovations for infants." New Zealand Medical Journal 126 (1379):86-89.

Ajwani, S, Tony Blakely, Bridget Robson, Martin Tobias, and M Bonne. 2003. Decades of disparity: Ethnic mortality trends in New Zealand 1980-1999 (Public Health Intelligence Occasional Bulletin No.16). Wellington, New Zealand: Ministry of Health, Public Health Intelligence Group and University of Otago.

ANZEA, and SUPERU. 2014. "Proposed evaluation standards for Aotearoa New Zealand." Author. http://www.anzea.org.nz/wp-content/uploads/2014/08/FMC562-Evaluation-StandardsA.pdf.

Baum, V, and V Clarke. 2006. "Using thematic analysis in psychology." Qualitative Research in Psychology 3 (2):77-101.

Bazeley, Pat, and Kristi Jackson. 2013. Qualitative data analysis with NVivo. 2nd ed. Los Angeles, CA: Sage Publications.

Buetow, S, and J Wellingham. 2003. "Accreditation of general practices: Challenges and lessons." Quality and Safety in Healthcare 12 (2):129-135. doi: 10.1136/ghc.12.2.19.

Came, H. 2012. "Institutional racism and the dynamics of privilege in public health."Unpublished doctorate, Waikato University.

Came, H. 2013. "Beginning to address institutional racism within the public health sector: Insights from a provider survey." Keeping up to date 38 (Autumn/Winter):1-9.

Came, H. 2014. "Sites of institutional racism in public health policy making in New Zealand." Social Science and Medicine 106 (0):214-220. doi: 10.1016/j.socscimed.2014.01.055.

Came, $\mathrm{H}$, and Susan da Silva. 2011. "Building political competencies for the transformation of racism in Aotearoa." Kotuitui 6 (1-2):113-123. doi: 10.1080/1177083X.2011.615332.

Came, H, and Tim McCreanor. 2015. "Pathways to transform institutional (and everyday) racism in New Zealand." Sites: Journal of Social Anthropology and Cultural Studies 12 (2):24-48. doi: 10.11157/sites-vol12isss2id290.

Coleman, Jonathan. 27 August 2015. "Rheumatic fever rates drop 24 per cent." New Zealand Government Accessed 10 September. https://www.beehive.govt.nz/release/rheumaticfever-rates-drop-24-cent.

Cram, F. 2014a. Equity of healthcare for Māori: A framework. Wellington, New Zealand: Ministry of Health.

Cram, F. 2014b. Improving Māori access to healthcare: Research report. Wellington, New Zealand: Ministry of Health.

Cunningham, Chris. 1995. He taura tieke: Measuring effective health services for Maori. Wellington, New Zealand: Ministry of Health.

Dow, Derek. 1999. Maori health and government policy 1840 - 1940. Wellington, New Zealand: Victoria University Press in association Department of Internal Affairs.

Durie, Mason. 1993. The CHI model: A culturally appropriate auditing model: guidelines for public health services. Wellington, New Zealand: Public Health Commission.

Durie, Mason. 1998. Whaiora: Māori health development. 2nd ed. Auckland, New Zealand: Oxford University Press.

Easton, B. 2002. The New Zealand health reforms of the 1990s in context. Applied Health Economics and Health Policy 1: 107 - 112.

Fleming, P. 2007. "Enhancing the empowerment agenda in health promotion through reflective practice." Reflective Practice 8 (73):315-330. doi: 10.1080/14623940701424827.

Fletcher, Ned. 2014. "A praiseworthy devise for amusing and pacifying savages? What the framers meant by the English text of the Treaty of Waitangi." Unpublished doctoral, Auckland University.

Freire, Paulo, and Ana Freire. 2004/1992. Pedagogy of hope: Reliving pedagogy of the oppressed (Original work published 1992). London, England: Continuum. 
Friedman, Mark. 2005. Trying hard is not good enough: How to produce measurable improvements for customers and communities. Victoria, Canada: Trafford.

Griffith, D.M, M Mason, M Yonas, E Eng, V Jefferies, S Pliheik, and B Parks. 2007. "Dismantling institutional racism: Theory and action." American Journal of Community Psychology 39:381-392. doi: 10.1007/s10464-007-9117-0.

Griffith, Derek, Erica Childs, Eugenia Eng, and Vanessa Jeffries. 2007. "Racism in organizations: The case of a county public health department." Journal of Community Psychology 35 (3):287302. doi: 10.1002/jcop.20149.

Hayward, Janine. 1997. "The principles of the Treaty of Waitangi." In Rangahau whanui national overview report, edited by Allan Ward, 475-494. Wellington, New Zealand: Waitangi Tribunal.

Health Promotion Forum. 2000. TUHA-NZ: Treaty Understanding of Hauora in Aotearoa New Zealand. Auckland, New Zealand: Author.

Health Promotion Forum. 2011. Ngā kaiakatanga hauora mō Aotearoa: Health promotion competencies for Aotearoa-New Zealand. Auckland, New Zealand: Author.

Healthcare Aotearoa. 2007. "Te wana quality programme." Healthcare Aotearoa Accessed 6 February. http://www.hca.org.nz/twa/.

Healy, Susan, Ingrid Huygens, and Takiwai Murphy. 2012. Ngāpuhi speaks. Whangarei, New Zealand: Network Waitangi Whangarei, Te Kawariki.

Huygens, Ingrid. 2006. "Discourses for decolonization: affirming Maori authority in New Zealand workplaces." Journal of Community and Applied Social Psychology 16:363-378. doi: 10.1002/casp.881.

Jansen, P, K Bacal, and Sue Crengle. 2008. "He ritenga whakaaro: Māori experiences of health services." Hospital 200:30-7.

Kelsey, Jane. 1991. "Treaty justice in the 1980s." In Nga take: Ethnic relations and racism in Aotearoa/ New Zealand, edited by Paul Spoonley, David Pearce and Cluny Macpherson, 108131. Palmerston North, New Zealand: Dunmore Press.

King, Annette. 2000. The New Zealand health strategy. Wellington, New Zealand: Ministry of Health.

Lafond, AK, Leslie Brown, and K Macintyre. 2002. "Mapping capacity in the health sector: A conceptual framework." International Journal of Health Planning and Management 17 (1):322. doi: 10/1002/hpm.649.

Lange, Raeburn. 1999. May the people live: a history of Maori health development 1900-1920. Auckland, New Zealand: Auckland University Press.

Marriott, Lisa, and Dalice Sim. 2014. Indicators of inequality for Māori and Pacific people [Working paper 09/2014]. Wellington, New Zealand: Victoria University.

Matike Mai Aotearoa. 2016. He whakaaro here whakaumu mō Aotearoa. Wellington, New Zealand: Author.

Mills, Anne, and Jonathan Broomberg. 1998. Experiences of contracting health services: An overview of the literature. London, England: University of London, School of Health and Tropical Medicine.

Ministry of Health. 1998. Whaia te whanaungatanga: Oranga whanau: The wellbeing of whanau: the public health issues. Wellington, New Zealand: Author.

Ministry of Health. 2003. Improving quality (IQ): A systems approach for the New Zealand health and disability sector. Wellington, New Zealand: Author.

Ministry of Health. 2004. A health equity assessment tool (equity lens) for tackling inequalities in health. Wellington, New Zealand: Author.

Ministry of Health. 2007. Whannau ora health impact assessment. Wellington, New Zealand: Author.

Orange, Claudia. 2011. The Treaty of Waitangi. 2nd ed. Wellington, New Zealand: Bridget Williams Books. 
Penno, E, R Gauld, and R Audas. 2013. "How are population-based funding formulae for healthcare composed? A comparitive analysis of seven models." BMC Health Services Research 13 (1):470.

Pōmare, Eru. 1980. Maori standards of health: A study of the 20 year period 1955-75: A report prepared for the Medical Research Council of New Zealand. Wellington, New Zealand: Medical Research Council of New Zealand.

Pōmare, Eru, and Gail De Boer. 1988. Hauora:Māori standards of health: A study of the years 19701984. Wellington, New Zealand: Medical Research Council and Department of Health.

Pōmare, Eru, Vera Keefe-Ormsby, Clint Ormsby, Neil Pearce, Papaarangi Reid, Bridget Robson, and Naina Watene-Haydon. 1995. Hauora: Māori standards of health 3: A study of the years 1970-1991. Wellington, New Zealand: Te Rōpū Rangahau Maori Research Centre.

Public Health Association. 2007. Generic public health competencies implementation: Issues for consideration. Wellington, New Zealand: Author.

Public Health Association. 2012. Te ture whakaruruhau: Code of ethical principles for public health in Aotearoa New Zealand. Wellington, New Zealand: Author.

Ramsden, Irihapeti 2002. "Cultural safety and nursing education in Aotearoa and Te Waipounamu."Doctoral dissertation, Nursing, Massey University.

Reid, P, and B. Robson. 2007. "Understanding health inequities." In Hauora Maori standards of health IV, edited by Harris R Robson B, 3-11. Wellington, New Zealand: Te Ropu Rangahau Hauora a Eru Pomare.

Salmond, George. 9 May 1988. Treaty of Waitangi and its implications for the health servicees (Memo 194/9, 349/17). Wellington, New Zealand: Department of Health.

Sheridan, Nicolette, Timothy Kenealy, Martin Connolly, Faith Mahony, Alan Barber, Mary Anne Boyd, Peter Carswell, Janet Clinton, Gerard Devlin, Robert Doughty, Lorna Dyall, Ngaire Kerse, John Kolbe, Ross Lawrenson, and Allan Moffitt. 2011. "Health equity in the New Zealand health system: A national survey." International Journal for Equity in Health 10 (1).

Signal, Louise. 1998. "The politics of health promotion: Insights from political theory." Health Promotion International 13 (3):257-263. doi: 10.1093/heapro/13.3.257.

Signal, Louise, Jennifer Martin, Papaarangi Reid, Christopher Carroll, Phillippa Howden-Chapman, Vera Keefe Ormsby, Ruth Richards, Bridget Robson, and Teresa Wall. 2007. "Tackling health inequalities: Moving theory to action." International Journal for Equity in Health 6 (12). doi: 10.1186/1475-9276-6-12.

Signal, Louise N., Mat D. Walton, Cliona Ni Mhurchu, Ralph Maddison, Sharron G. Bowers, Kristie N. Carter, Delvina Gorton, Craig Heta, Tolotea S. Lanumata, Christina W. McKerchar, Des O'Dea, and Jamie Pearce. 2013. "Tackling 'wicked' health promotion problems: a New Zealand case study." Health Promotion International 28 (1):84-94. doi: 10.1093/heapro/das006.

Upton, Simon. 1991. Your health and the public health: A statement of government health policy. Wellington, New Zealand: Ministry of Health.

Waitangi Tribunal. 2014. Te paparahi o te raki [Wai 1040]. Wellington, New Zealand: Author.

WHO. 1986. Ottawa charter for health promotion. In Proceedings of the 1st international conference on health promotion. Ottawa, Canada: World Health Organization. 